\title{
Aprendiendo a Vivir juntos en una sociedad PLURAL: APORTE DE LA EDUCACIÓN RELIGIOSA ESCOLAR Católica (EREC)
}

\author{
LEARNING TO LIVE TOGETHER IN A PLURAL SOCIETY: \\ CONTRIBUTION FROM CATHOLIC SCHOOL RELIGIOUS \\ EDUCATION (CSRE)
}

\author{
Alfonso Valenzuela Aguirre ${ }^{26}$ \\ Santiago, Chile
}

\begin{abstract}
RESUMEN
El artículo indaga sobre el propósito de la enseñanza religiosa en el contexto escolar pluralizado y diverso. Ella, más que una catequesis escolar, es una experiencia de aprendizaje que contribuye al desarrollo de la religiosidad y al dialogo de la fe con la cultura y la ciencia. Su propósito es de carácter religioso, es decir, es conocer y amar a Dios, y con ello al prójimo, para reflexionar y actuar desde esta experiencia. Es definida como un espacio de encuentro y dialogo de la diversidad que contribuye a la calidad educativa.
\end{abstract}

\section{Palabras claves}

Pedagogía religiosa, diálogo fe y cultura, religiosidad, experiencia religiosa, aprender a vivir juntos.

\begin{abstract}
The article explores the purpose of religious education in the pluralized and diverse school context. More than school catechism, it is a learning experience that contributes to the development of religiosity and the dialogue among faith, culture and science. This article has a religious purpose per se, that is to say, it aims at knowing and loving God, as well as our fellow men in order to reflect and act from this experience. It offers a place for meeting and dialogue about diversity, which contributes to educational quality.
\end{abstract}

\section{KeYWORDS}

Religious pedagogy, faith and culture dialogue, religiosity, religious experience, learning to live together. 
Alfonso Valenzuela Aguirre | Aprendiendo a vivir juntos en una sociedad plural: aporte de la Educación Religiosa Escolar Católica (EREC)

\section{INTRODUCCIÓN}

La convivencia social, comunitaria e interpersonal es una realidad antropológica que permite trascender al ser humano y salir de sí mismo para construirse en relación a otras realidades. Somos seres relacionales que construimos nuestra mismidad en y con otros, en un proceso histórico y cultural que a la vez construimos también en conjunto con los demás.

Cada persona y grupo social, desde su identidad, aporta a la construcción de la convivencia. Para ello, ponen a disposición de la sociedad sus mega-relatos a través de procesos de aprendizajes que se instalan progresivamente. El ser humano va construyendo su identidad personal y social en los procesos de socialización desde las vivencias de apego en la primera infancia hasta el momento de su muerte (Pérez Gómez, 1998, p. 20).

En nuestra sociedad un actor relevante es la Iglesia Católica. Si bien es verdad que en las últimas décadas ha disminuido su adhesión como institución (Press Reader, 2018) y la confianza en ella (Latinobarómetro, 2017), no es menos cierto que el planteamiento católico forma parte muy importante de nuestra identidad. Convicciones fundamentales que, aunque pueden tener distintas interpretaciones, en su núcleo fundamental no están en discusión. Estas tienen relación con el aporte del catolicismo en nuestra historia: la centralidad de la dignidad de la persona humana como fin y nunca como medio, la relevancia de la solidaridad como valor necesario de ser institucionalizado, el ponerse en el lugar del otro (misericordia), el valor de la justicia como criterio para progreso social, el valor del acto religioso espontáneo, etcétera.

Lo anterior se ha enseńado y aprendido en las instancias de socialización que la sociedad organizada ha ido estableciendo. Entre ellas, la familia, los medios de comunicación y diversas instituciones donde se vive y aprende a vivir en relación con otros. De esta forma, la Escuela, en nuestra conformación histórica, ha sido una instancia clave para configurar la identidad social, a través de la intencionalidad pedagógica que se concreta en el currículum y que obedece en parte 
a lo que somos como sociedad, pero también a lo que esperamos ser y para lo cual formamos a las nuevas generaciones (Cox, s/f).

A través de la Escuela, en Chile, como en muchas sociedades, la Iglesia Católica ha educado religiosamente a los estudiantes a través de programas de formación religiosa que han respondido explícita o implícitamente a lo que el contexto cultural les ha solicitado, para entregar fundamentalmente valores cristianos ligados a la identidad que la nación ha reconocido como propios, aportando a construir una sociedad que se ha ido considerando homogénea.

Hoy el contexto ha cambiado radicalmente. Ya no existe una cosmovisión hegemónica, o al menos muchos sectores no reconocen la tradicional cosmovisión cristiana como propia (Campos, 2008). Más aun, se vivencia una suerte de necesidad, por parte no menor de la población, por liberarse, como lo intentó la Ilustración, de la hegemonía religiosa, planteando que el Estado laico, por definición, debe excluir de la esfera pública el relato religioso, buscando formar en una ética desprendida de la religión (Campos, 2008).

El núcleo de sentido otorgado principalmente por la religión, y que hasta hace poco fue muy importante, hoy se ha debilitado, lo que explica, en parte, la aparición de un problema que afecta seriamente a la convivencia social. Efectivamente, la visión común del proceso social y de los valores que constituyen su poder cohesionador se han fraccionado a partir de la subjetivización de la realidad cotidiana, producto del pluralismo y el multiculturalismo de la sociedad globalizada (Campos, 2008). Esta subjetivización y la consiguiente exigencia de construir la identidad personal y comunitaria en base a las propias opciones, sin referentes institucionales, ha fraccionando al mismo sujeto (personal y colectivo) (Touraine, 1997), por lo que se hace necesario volver a él apuntando a su desarrollo y protagonismo.

En este nuevo contexto social se inserta el currículum religioso en diálogo con la cultura como visión de la identidad que queremos construir a nivel colectivo, asumiendo un tiempo, un espacio común. Así se transforma la escuela en un campo de reflexión y acción donde se reflexionan los procesos sociales, se debate sobre la cosa pública y se 
educan los valores que sostienen la convivencia diaria (Peña, 2007). La enseńanza religiosa debe asumir un contexto de incertezas donde este sujeto desea irrumpir y donde no se vislumbra la hegemonía de ningún megarelato (Pérez Gómez, 1998).

En este escenario nos movemos. Es aquí donde toma sentido el desafío de la convivencia y la consiguiente definición, construcción y distribución de los mega-relatos curriculares, que den cohesión y sentido común a una multiplicidad de opciones de sentido (PNUDUNICEF, 2014). Esto particularmente en Chile, donde irrumpen sectores que, quizá por reacción a antiguas hegemonías, actúan incluso con violencia para no reconocer las diferencias e imponer las posturas propias. Es el caso de sectores de estudiantes, barras bravas, delincuencia e incluso movimientos religiosos y políticos. Hechos acaecidos últimamente en nuestro país parecen mostrar que el reconocimiento de los derechos propios no parece acompañarse con el reconocimiento de los derechos de los otros, manifestándose una dificultad no menor para compartir la casa común.

Por lo anterior, un tema central que debemos enfrentar en la clase de Religión es la convivencia, es decir, el aprender a vivir juntos (Congregación para la Educación Católica, 2014), en medio de una convivencia social plural, cuyos sentidos y comprensiones se construyen desde una multiplicidad de sentidos simbólicos, dando origen a una síntesis que se va construyendo desde la legitimidad y diversidad de comprensiones e interpretaciones que se van dando sobre la realidad humana.

Para la educación religiosa católica es importante plantearse el objetivo de contribuir a la significación de estos referentes de sentidos desde su propia identidad que le da su fe en Jesucristo, sus enseñanzas y acciones (Congregación para la Educación Católica, 2014). Como también reflexionar a partir de lo que aportado a la convivencia social y la cultural, a lo largo de la historia humana, fundados de esa fe. No hay razones a priori para justificar la privatización de la fe religiosa o para pedir que no sea considerada como un saber y experiencia válida y legitima, que ofrece un punto de vista abierto al diálogo y 
la razón pública en el debate de carácter plural (Congregación para la Educación Católica, 2014).

Desde esta creencia en Jesús que manifestó la cercanía del Reinado de un Dios que camina con su pueblo, surge la pregunta sobre cómo ayudar a construir el sentido común desde la pluralidad de visiones cosmologizadoras; es decir, cómo, desde las opciones de la Iglesia, se puede contribuir a la construcción de relaciones humanas que nos ayuden a vivir juntos. Esto, aunque existan algunos interlocutores que niegan la legitimidad de la presencia de la institución religiosa en el espacio público y particularmente en la escuela (Yaksic, 2011, p. 61), relegando su labor educativa al interior de su propia organización (capillas, parroquias y sacristías).

\section{El aporte de la Iglesia Católica en la CONFiguración DE LA IDENTIDAD NACIONAL}

Para los católicos, la iglesia es "un signo y salvaguardia del carácter trascendente de la persona humana” (GS. No76), y estamos convencidos que su cosmovisión es un factor fundamental para aprender a vivir juntos. La Iglesia siempre lo ha considerado un deber, no solo un derecho (RN. No1). Por esta razón, no podemos considerar válido relegar la experiencia religiosa sólo a un acto privado, sin posibilidad de expresión e incidencia en la vida pública. Cuando las razones religiosas se convierten en argumentos políticos, los creyentes han de hacer lo posible para justificar apropiadamente sus argumentos, para que las razones religiosas dadas públicamente sean accesibles a cualquier persona (Yaksic, 2011, p. 43). La Iglesia sabe que, en el espacio público, donde se construye el bien común, tiene que dar razón de la esperanza (1 Pe 3,15), o hacer "comunicable razonablemente" el contenido de la fe.

Esta convicción de ser un aporte necesario para la construcción de la humanidad, nace y se funda en la predicación de Jesucristo, interpretada por la comunidad cristiana desde sus orígenes. Para la primitiva Iglesia, Jesús era el mensajero de Dios portador de la Buena 
Nueva que proclamaba el Reino de Dios. El traía el evangelium. Él manifiesta la buena nueva de Dios. Jesucristo manifiesta a Dios porque Él "quiere ser visto, oído y tocado realmente en su Palabra Viva, hecha carne, a fin que nosotros, yendo a su encuentro, entremos en comunión con Él de un modo totalmente nuevo" (Von Balthasar, 1979, p. 22). Este anuncio lleva consigo la posibilidad de una respuesta que involucra no solo la vida personal, sino también social y comunitaria; impregna todas las formas de conocer y comprender la realidad humana. El mensaje de Jesucristo está dirigido a una comunidad de creyentes y es entendido así por dicha comunidad, que lo hace propio y lo comunica adecuadamente en un espacio social y cultural (Juan Pablo II, 1988).

Consecuente con esto, se sigue un nuevo modo de vida y, por tanto, una ética fundada en una vivencia religiosa. Es la exigencia para los que optan por ella, de la opción por el seguimiento de Jesús y la adhesión al Reino y la justicia que les es consecuente (Mateo 6,33). La acción de Jesús lleva consigo corolarios éticos innegables que nacen de una relación profundamente religiosa con un Dios al que llamaba $A b b a$, es decir, Padre, más aún, "Papá” (Marcos 14,36) Consecuente con esta perspectiva es fundamental para la enseñanza religiosa diferenciar, como también complementar, las visiones cosmologizadoras de las distintas formas del saber humano: ciencia, filosofía y religión, que permitan conformar, al estudiante, una visión integral de la realidad humana. Al respecto, Estrada sostiene que "junto a ellas (filosofía y ciencia) existen también creencias religiosas, que no solo responden racionalmente a las preguntas humanas, como pretenden la ciencia y la filosofía, cada una en su ámbito, sino que ofrecen orientaciones y valores que apelan a la razón, pero también a las pasiones, a los afectos y necesidades vitales" (Estrada, 2001, p. 29).

La opción por Dios implica una decisión de fe, es decir, una respuesta creyente razonada. Por lo tanto, se trata de una confianza razonable, pues la decisión de fe nunca puede ser puramente subjetiva y arbitraria sino plenamente racional y responsable (cf. 1 Pe 3,15). Esto lleva a fundamentar la significación de Jesucristo (Von Balthasar, 
1979). De ahí que se haga necesario mostrar nuestro ser cristiano de un modo diferente, a partir de la figura de Jesús y su mensaje, y no como lo hacemos muchas veces, desligados de una verdadera experiencia religiosa. El propósito o consecuencia del anuncio del Reino y voluntad de Dios, manifestado en las bienaventuranzas y en la vida de Jesús, nos desvela una verdadera humanidad que supone una humanización radical, que se manifiesta en la solidaridad humana, incluso para con el adversario. Es a partir de Jesús, el hombre auténtico y verdadero, que es preciso practicar esta humanización radical de las bienaventuranzas (Von Balthasar, 1979)

Destacar la humanidad del cristianismo es, a la vez, un puente clave para ofrecer nuestra fe como una visión comprehensiva de la realidad que contribuye a dar respuestas a las preguntas fundamentales de la persona humana, pero que además, desarrolla por medio de la experiencia comunitaria la relación con los demás (Von Balthasar, 1979): la enseñanza religiosa impulsa la búsqueda del bien, de la tolerancia y la paz porque contribuye a establecer una relación especial con el mundo de la vida que rodea al estudiante, "afirmando y cultivando la dignidad que le es propia” (GS. No9); el mensaje de Jesús a la vida cotidiana implica un aporte a la convivencia interpersonal, ofreciéndole un sentido profundo al tocar aspectos ligados a preguntas religiosas fundamentales con consecuencias para la interrogante sobre cómo vivir juntos hoy día.

Esta humanidad vivida y anunciada desde una profunda experiencia religiosa, lo vivió la Iglesia ante el desafío de decir una palabra en medio de las transformaciones del mundo moderno, a través del Concilio Vaticano Segundo. Este mensaje eclesial necesitamos presentarlo hoy como un desafío de primer orden para la clase de Religión. La experiencia de Jesús leída por la tradición de la Iglesia, ratificada en el Vaticano Segundo, nos hace conscientes de nuestra identidad, de ser una comunidad que comparte creencias y que las considera un bien para un proceso de humanización integral: "Por eso, el Concilio, como testigos y portavoz de la fe de todos el pueblo de Dios congregado por Cristo, no puede dar respuesta mayor de 
solidaridad, respeto y amor a toda la familia humana, que la de dialogar con ella acerca de todos los problemas, aclarándoselos a la luz del Evangelio" (GS. No3).

Si bien como Iglesia estamos convencidos de nuestro derecho y deber a participar en el dialogo público, contribuyendo de este modo a una convivencia más justa, equitativa y libre, necesitamos también reconocer que nuestro modo de participar hoy debe ser diferente $y$, por tanto, requerimos aprender a proponer nuestro aporte en clave religiosa, con diálogo y con pedagogía (Congregación para la Educación Católica, 2014). Por eso, es una tarea para la Educación Religiosa, junto con desarrollar la religiosidad de los estudiantes (CECH, 2005), liderar el logro de ciertas metas valiosas para el proceso educativo, conocidas como objetivos transversales $(\mathrm{CECH}$, 2005), abriéndose a los grandes problemas del mundo e invitando a los estudiantes a un mayor conocimiento e integración en la vida cívico-social y en la Iglesia universal (CECH, 2005).

De este modo, podemos participar del proceso de significación y definición de los valores que orienten y regulen nuestra convivencia social desde nuestras creencias religiosas y desde nuestras opciones. Para eso es importante que los cristianos en general, y el profesor de Religión en particular, conozcan e internalicen comprensivamente esas opciones más allá de los valiosos sentimientos personales o del legítimo valor que le dan a su experiencia religiosa personal. En este sentido, el reto de redescubrir nuestra identidad comunitaria y heredera de una tradición cuyo núcleo está en la experiencia religiosa de Jesús, es de primera importancia.

Desde lo anterior y en el contexto de disgregación social que vivimos, donde nace la pregunta sobre cómo aprender a vivir juntos, se hace necesario establecer un diálogo con otras comprensiones y visiones de la vida humana, buscando juntos el sentido a la convivencia cotidiana (Congregación para la Educación Católica, 2014). Nuestro mayor desafío está en el aporte que podemos dar a las nuevas relaciones sociales y culturales que se van gestando, especialmente la confianza, como un camino para la dignificación 
de la persona humana en la cotidianidad del mundo de la vida. Para esto, la clase de Religión confesional -que implica el aporte desde una particularidad, pero mayoritaria y tradicional- a la vez inserta en un contexto de diversidad, puede ser un aporte significativo, tanto para dar un significado a la experiencia religiosa de donde surge nuestra visión del mundo, como para fundamentar a otros el por qué pensamos en la centralidad del ser humano y en los principios y valores éticos que propiciamos (CECH, 2005).

Podremos contribuir en el desarrollo del estudiante para que se experimente trascedente y pueda fundar su vida en el modelo y mensaje de vida de Jesucristo, o al menos ayudarle a que conozca por qué pensamos y optamos de este modo. Podremos ayudarles a comprender los dones de la libertad, de su dignidad, como inviolables, y que desde ellos pueden posicionarse en la vida y aspirar a una plenitud de ella.

¿Qué ideales de nuestra fe tenemos que testimoniar proféticamente en la sala de clases con las mismas exigencias de otros ramos, con métodos y contenidos adecuados al ámbito educativo, para motivar a los estudiantes a vivir los ideales del cristianismo? Pareciera que, en definitiva, tenemos que preguntarnos por nuestra visión de ser humano y la sociedad; por los principios evangélicos que los sustentan; por el diálogo con otras visiones comprensivas, éticas y morales que dialogan en la esfera pública; por el valor religioso de nuestra identidad católica, para que todo esto podamos transformarlo en contenidos para la enseńanza religiosa, que motiven al estudiante a vivir la vida con la estatura de Cristo.

Tenemos el desafío de reflexionar sobre los contenidos temáticos y los principios evangélicos que nos permitan fundamentar un humanismo cristiano que dialoga con las nuevas circunstancias sociales; para que la sala de clases, junto con ser "verdaderos laboratorios de la vida social, sean también laboratorios de humanidad, de diálogo con otras visiones del mundo" (Congregación para la Educación Católica, 2014, No74). 
Alfonso Valenzuela Aguirre | Aprendiendo a vivir juntos en una sociedad plural: aporte de la Educación Religiosa Escolar Católica (EREC)

EVANGELIZAMOS EN UN MUNDO DE PLURALIDAD DE CREENCIAS

Uno de los desafíos más relevantes de los profesores de Religión en la sala de clases es el pluralismo religioso y la multiplicidad de opciones de vida y posturas de las familias, además de las que espontáneamente suelen surgir entre los mismos estudiantes en las etapas más avanzadas de su desarrollo escolar. Ellos tienen acceso hoy a variadas y diversas fuentes de información, y pueden buscar desde muchos otros referentes de sentidos, prescindiendo de la exclusiva reflexión y mediación de la Escuela.

Las condiciones culturales y sociales, en muchos casos, hacen aparentemente innecesaria incluso la pregunta por Dios, sobre todo si la respuesta a esta pregunta está mediada institucionalmente por una institución desautorizada. La expresión religiosa ha cambiado y se vive desde las propias perspectivas, por opción extrainstitucional (Luckmann, 2008), por lo tanto, la adhesión no implica una copertenencia y puede configurarse más desde la satisfacción de pequeñas trascendencias (Luckmann, 2008). Parece difícil conectar lo religioso con las preguntas fundamentales que, además, muchas veces no se formulan y, por lo tanto, no necesitan ser respondidas religiosamente. Existe además una espiritualización de formas de solidaridad social como los ecologismos, los movimientos por la tierra, las que adquieren características cuasi religiosas o espirituales -por efecto de sentimientos compartidos que son hipostasiados (Durkheim, 2007)-, que otorgan sentido, constituyendo verdaderas comunidades de sentido, que a veces constituyen una comunidad moral con rasgos de pseudoreligiosos.

En el ámbito del desarrollo social y cultural, un desafío ineludible es la definición del lugar que ocupa la religión en el espacio público, en una cultura que se ha visto influenciada por las ideas liberales y el libre tránsito en la esfera pública de pluralidad de dispositivos de sentido, que incluso son considerados salvaguardia de valores que nacieron en las concepciones religiosas: "Los principios seculares han 
sido el marco utilizado para proteger los valores fundamentales como la libertad, la igualdad y el respeto mutuo. Con miras a preservar la estabilidad de una sociedad plural, el liberalismo insiste en que las convicciones morales y religiosas deben permanecer como un asunto privado. La democracia y la tolerancia, se ha argumentado, estarían mejor preservadas si las convicciones religiosas fueran removidas de la conversación público-política. Esta tendencia liberal moderna, que empuja los esquemas comprehensivos y las visiones sustantivas de la vida hacia el ámbito de lo privado, representa un dilema mayor para la fe cristiana" (Yaksic, 2011, p. 15)

Desde aquí aparece central la pregunta para el profesor: ¿cómo educar religiosamente en este mundo de incerteza, plural, multidimensional y -aparentemente- increyente, en el cual han entrado a la convivencia cotidiana muchas de las ideas liberales (autodeterminación), donde no se formula, necesariamente, la pregunta por el sentido, donde no se necesita constituir una comunidad?

En este contexto entra la falsa dicotomía entre religión y ética, como si la primera no tuviera repercusiones en la vida humana cotidiana y la segunda no pudiera ser fundamentada también por un mensaje religioso; Estrada explicará que "el problema es que el hombre sigue haciéndose preguntas metafísicas, es decir, que desbordan lo positivo, lo fáctico dado, y que necesitan de cosmovisiones dadoras de identidad" (Estrada, 2001, pág. 23). Justamente, el mensaje de Jesús y su predicación integran ambas dimensiones: la trascendente y la inmanente. Desde una relación con Dios no solo no eludimos la cotidianidad, sino que la alimentamos para acercarla cada vez más a la invitación de un Dios que está presente en la historia. En la etapa de la formación de la persona es fundamental aceptar el desafío de construir un sentido personal y social desde las creencias y valores. Como dirá Estrada (2001), "no es posible dejar vacía la cultura de valores, ideales, creencias e ideas que canalizan la conducta, determinan las reglas de juego sociales y ofrecen modelos de identidad" (p. 23). Por otro lado, desde lo cotidiano podemos leer los signos de los tiempos para distinguir, en clave de discernimiento, 
lo que conduce a mayores condiciones humanas. Lo dicho trae consecuencias para la formación religiosa escolar en un contexto sociocultural diverso. El mensaje fundamental de Jesús puede entrar justamente en diálogo, como oferta de humanización, aportando a la vida personal y social y dando fundamento a valores compartidos, enriqueciéndolos. Valores de la justicia, fraternidad, diálogo, respeto, solidaridad, entre otros, constituyen contenidos claves que pueden ser compartidos y enriquecidos por el testimonio de una persona, como Jesús que encarna un modo de ser humano lleno de sentido y que ha motivado la acción de muchos en la historia de Chile que han promovido los derechos de las personas de manera heroica. La fe religiosa y el amor a Dios inspiraron los valores de la "Cantata de los Derechos Humanos", fundamentó el amor al prójimo de san Alberto Hurtado con su lenguaje teológico, o "el alma de Chile" del Cardenal Silva; influyó, con su lenguaje religioso, para levantar una cultura justa, solidaria, que respeta al otro, porque comparte la misma dignidad de hijo de Dios.

Por tanto, es perfectamente válido plantear la viabilidad de una formación religiosa escolar ligada a valores y principios que orientan la vida en común desde el anuncio explícito del Evangelio. Plantearlo así puede ayudar al diálogo con visiones que comparten principios y valores desde otros horizontes de sentido, dando razón en clave de fe, que para el cristiano una vida justa se descubre como consecuencia de una experiencia religiosa de encuentro con el Dios de Jesús que vino a dar a conocer la cercanía del Reino.

\section{ObJetivo de la EREC}

La inclusión de la asignatura de Religión en el currículum escolar completa la acción educadora de la institución escolar. Esto porque, además del ámbito lingüístico y comunicativo, matemático, artístico, etc., al considerar en el proceso formativo de la persona su dimensión trascendente, espiritual y moral, su oferta formativa se hace más plena e integral (CECH, 2005). 
Por otro lado, la Iglesia nos llama a que en la institución escolar demos a conocer lo que de hecho constituye la identidad del cristiano y lo que los cristianos coherentemente se esfuerzan por realizar en sus vidas (CECH, 2005). "Desde esta perspectiva se entiende la educación religiosa como un elemento fundamental de la acción educativa de la Iglesia dirigida a conseguir una adecuada síntesis entre la fe y la cultura para ofrecer una óptica cristiana de la realidad. Se afirma que la EREC debe abrirse a una visión de los grandes problemas del mundo y debe invitar a los alumnos y alumnas hacia un mayor conocimiento e integración de la vida cívico-social y en la Iglesia universal" (CECH, 2005, pp. 12-13).

La asignatura de Religión Católica llama a la integración progresiva entre la fe, cultura y vida. Se afirma: "la EREC quiere acompañar al alumnado, iluminando con los contenidos explícitos de la fe católica tanto su proceso evolutivo como la asimilación de las culturas que influyen en los centros educativos" (p. 13). Para esto, se insiste que:

"... la fe debe inculturarse, es decir, tiene que comprenderse y expresarse según los códigos interpretativos de los miembros de cada comunidad humana, según lo indica el magisterio. Puede recordarse a este propósito que, como dijera Papa Juan Pablo II. '.. una fe que no se hace cultura, es una fe no plenamente acogida, no enteramente pensada, no fielmente vivida"' (CECH, 2005, p. 13).

El Programa de Religión del año 2005 invita a complementar, por lo menos desde una visión más teórica, la transmisión del mensaje cristiano con una visión pastoral/catequística con una mirada hacia una educación religiosa escolar que debe cumplir los mismos fines que otras asignaturas.

Esta idea se fundamenta en que la EREC complementa el polo "religioso" con el polo de la religiosidad, manteniendo su carácter de enseñanza religiosa. La EREC sostiene que su objetivo "es una acción que pretende formar la religiosidad (...) desde la perspectiva de la fe cristiana, tal y como la vive y proclama la Iglesia católica" (CECH, 2005, p. 16). 
Colocar este objetivo en el desarrollo de la religiosidad quiere decir para la EREC, que: "Al hacer referencia a la 'religiosidad' y no a la 'religión' el acento está en el polo personal, es decir, en el desarrollo en el interior del individuo de las más profunda de sus dimensiones ontológicas en vistas de fundar y/o desarrollar una relación personal con 'lo trascendente'. Esto es distinto a querer privilegiar exclusiva o impositivamente el polo más institucional, por así decir, el cual podría concebirse como adscripción de las personas a un corpus ya constituido de elementos doctrinales y rituales de una religión determinada" (CECH, 2005, p. 16).

Aclarada esta perspectiva, el Programa sostiene que "esta clarificación - polo puesto en la religiosidad- es importante, pues hace razonablemente posible una EREC amplia, ecuménica, respetuosa para todos los que buscan una formación integral. Por lo tanto, la EREC es posible, también, en un contexto social de pluralismo ideológico, filosófico y religioso. Ella aporta a experiencias multidisciplinares que surjan en el contexto escolar, pudiendo colaborar en proyectos interdisciplinares, e incluso liderando proyectos transdisciplinarios que se propongan (...) En todo caso, siempre será un aporte al dialogo entre opciones religiosas distintas, tal como lo hemos desarrollado antes en la fundamentación de la EREC” (CECH, 2005, p. 16).

Luego, en la EREC está la comprensión de la confesionalidad doctrinal abierta al dialogo con el mundo en su polo más cultural. Sin embargo, hemos tenido un problema de comprensión para verla, un déficit de saber para expresarla y una gran falla al implementarla. A partir de estas primeras notas, nuestra tarea puede ser transitar curricular y pedagógicamente desde la visión de la EREC como catequesis -lectura reducida de la EREC- a una concepción de confesionalidad dialógica con la cultura y el diálogo interreligioso, para la construcción de una ciudadanía basada en el Evangelio y un compromiso social cristiano, es decir, una visión amplia, que tiene continuidad con lo definido por la CECH en el Programa de Religión Católica, manteniendo su condición de enseñanza religiosa confesional, que más que la catequización del estudiante, lo invita 
a comprender el valor de la experiencia religiosa en su desarrollo integral, respetando, especialmente el profesor, la tradición religiosa del estudiante. Lo esencial es que ellos amen a Dios y ese amor los lleve a una conducta de aceptación y dialogo con sus próximos.

Este tránsito se desarrolla desde la natural inclinación del ser humano a la trascendencia y al natural desarrollo de la religiosidad. El patrimonio cultural de la Iglesia y su fe en Jesucristo es la experiencia que, constituida curricularmente en conocimiento para la enseńanza y pedagogía, es una herramienta fundamental para el desarrollo de la religiosidad. El dialogo entre fe y cultura, fe y ciudadanía, se hace más rico desde esta confesionalidad, que, respetando otras posturas, contribuye a tomar opciones, dialogar con lo diferente y a convivir con lo que le parece extraño o distante, siempre con el objetivo de religar a Dios como fuente de la dignidad de la persona humana. En este sentido, Von Balthasar (1979) nos ofrece una idea central para el desarrollo del saber religioso en la escuela pluralista, que acepta la experiencia religiosa como apertura del otro: "Cuanto mejor se prepare el corazón humano para acoger la manifestación del misterio divino en la fe y en el amor, tanto más profundamente será afectado por él y con tanta mayor fuerza se apropiará de él” (p. 27).

Esta visión de la clase de Religión confesional, abierta al dialogo con la cultura, que aporta fundamento para todos los aspectos de la vida humana, iluminada por el Evangelio, se encuentra ampliamente respaldada por el magisterio eclesial. En GS se afirma: "Los gozos y las esperanzas, las tristezas y las angustias de los hombres de nuestro tiempo, sobre todo de los pobres y de cuantos sufren, son a la vez gozos y esperanzas, tristezas y angustias de los discípulos de Cristo. Nada hay verdaderamente humano que no encuentre eco en su corazón. La comunidad cristiana está integrada por hombres que, reunidos en Cristo, son guiados por el Espíritu Santo en su peregrinar hacia el Reino del Padre y han recibido la buena nueva de la salvación para comunicarla a todos. La Iglesia, por ello, se siente íntima y realmente solidaria del género humano y de su historia" ( $\left.\mathrm{n}^{\circ} 1\right)$. 
Por otro lado, en el documento "Educar al diálogo intercultural en la escuela católica: vivir juntos para una civilización del amor", se sostiene que: "Se debe subrayar que la enseñanza escolar de la Religión católica tiene finalidades específicas, que la distingue de la catequesis. Mientras que esta última promueve la adhesión personal a Cristo y la maduración de la fe cristiana, la enseñanza escolar transmite a los alumnos los conocimientos sobre la identidad del cristianismo y de la vida cristiana" (2014, N²4). Al hacer esta distinción, la Congregación para la Educación Católica propone para la clase de Religión "ensanchar los espacios de nuestra racionalidad, volver a abrirla a las grandes cuestiones de la verdad y del bien, conjugar entre sí la teología, la filosofía y las ciencias, respetando plenamente sus métodos propios y su reciproca autonomía, pero siendo también conscientes de su unidad intrínseca. En efecto, la dimensión religiosa es intrínseca al hecho natural, contribuye a la formación global de la persona y permite transformar el conocimiento en sabiduría de vida" (2014, N²4).

En este mismo numeral la Iglesia propone un desafío para la escuela católica y, con ello, a los profesores de Religión: “... con la enseñanza católica la escuela y la sociedad se enriquecen con verdaderos laboratorios de cultura y de humanidad, en los cuales, descifrando la aportación significativa del cristianismo, se capacita a la persona para descubrir el bien y para crecer en la responsabilidad; para buscar el intercambio, afinar el sentido crítico y aprovechar los dones del pasado a fin de comprender mejor el presente y proyectarse conscientemente hacia el futuro" (Congregación para la Educación Católica, 2014, N74).

Respecto de la pedagogía religiosa como saber experto en el ámbito escolar, el documento ya citado en el párrafo anterior, insiste en que: “... el status de disciplina escolar coloca la enseñanza de la Religión en el currículo junto a las otras disciplinas, no con carácter accesorio, sino en el contexto de un necesario diálogo interdisciplinar" (No74). Esto significa que: "Como consecuencia, para alcanzar los objetivos de un ensanchamiento de los espacios de nuestra racionalidad y 
para sostener calificadamente el dialogo interdisciplinar y el dialogo intercultural, se muestra eficaz la enseńanza confesional de la religión” (Congregación para la Educación Católica, 2014, No75).

\section{LA EDUCACIÓN RELIGIOSA ES RELIGIOSA}

En la alocución de clausura del Concilio Vaticano II, el Papa Pablo VI se preguntó por el valor religioso del Concilio. Al respecto, sostuvo que: "decimos religioso por la relación directa con Dios vivo, relación que da la razón de ser de la Iglesia y de cuanto ella cree, espera y ama, de cuanto es y hace" (No1). Nosotros queremos preguntarnos por el valor religioso de nuestro actuar educativo y pedagógico. Es decir, nos podemos preguntar por nuestra relación educativa/pedagógica con Dios; la razón de ser de la Iglesia en la escuela, pero sobre todo por lo "que ella cree, espera, ama, por lo que es y hacemos por la construcción del Reino de Dios" (No1).

La pedagogía en Religión será religiosa en primer lugar, si "queremos seguir y anunciar a Cristo y buscamos el Reino de Dios y su justicia" (Pablo VI, 1965, No1). Parafraseando este discurso diríamos que es el vivo sentir de la enseñanza religiosa "conocer el mundo moderno para acercarse a él, comprenderlo, de penetrar, de servir, de evangelizar a la sociedad que lo rodea y de seguirla, por decirlo así, de alcanzarla casi en su rápido y continuo cambio" (Pablo VI, 1965, No4). La educación religiosa escolar no la queremos entender como una especie de apología ante el desarrollo humano que se opone a la verdad de la fe, sino más bien en cuanto ella hace descubrir en ese joven la dimensión religiosa que tienen las distintas dimensiones de la vida humana, que puede asumir en su proyecto de vida, que además es un proyecto junto a otros.

El Papa Pablo VI nos llamó a "notar cómo la religión de nuestro Concilio ha sido principalmente la caridad" (1965, No1). Para él, el Concilio ha logrado que la "religión del Dios que se ha hecho hombre, se ha encontrado con la religión - porque tal es- del hombre que se hace Dios [...] porque una gran simpatía lo ha inundado todo" 
(No2). Por este encuentro, el Papa sostiene: "El descubrimiento de las necesidades humanas -y son tanto mayores, cuanto más grande se hace el hijo de la tierra- ha absorbido la atención de nuestro Concilio... somos promotores del hombre" (Pablo VI, 1965, No5). Todo un objetivo curricular de la enseñanza religiosa.

Asumiendo esta perspectiva conciliar, ella puede reflexionar sobre su vocación religiosa: (la Iglesia) "ha reconocido su vocación fundamental a una plenitud de derechos y a una trascendencia de sentido; sus supremas aspiraciones a la existencia, a la dignidad de la persona, a la honrada libertad, a la cultura, a la renovación del orden social, a la justicia, a la paz, han sido purificadas y estimuladas; y a todos los hombres se ha dirigido la invitación pastoral y misional a la luz evangélica (Pablo VI, 1965, No6)”.

Nos dirá Pablo VI (1965): "La orientación de nuestro actuar es la de servir al hombre" (No6). La Iglesia se ha declarado sirvienta de la humanidad y toma una dirección antropocéntrica: "Quien observa este prevalente interés del Concilio por los valores humanos y temporales no puede negar que tal interés se debe al carácter que el Concilio ha escogido como programa y deberá reconocer que ese mismo interés no está jamás separado del interés religioso más auténtico debido a la caridad, que únicamente lo inspira (donde está la caridad allí está Dios) o a la unión de los valores humanos y temporales y promovida siempre por el Concilio: esté se inclina sobre el hombre y sobre la tierra, pero se eleva al Reino de Dios" (No7).

La clase de Religión tiene una dimensión antropocéntrica, su objeto de estudio es crear las condiciones de posibilidad educativo/ pedagógicas, para que, reflexionando con los estudiantes, su saber experto pueda desarrollar la dimensión espiritual/trascendente de los estudiantes y su consecuente relación con Dios. El centro del contenido religioso es religar al hombre con Dios y contribuir al descubrimiento de la dinámica salvadora/religiosa propuesta por Dios en la revelación, que compromete a la persona consigo misma y con los demás en la construcción de la realidad humana, según el orden propuesto por la tradición religiosa que hemos heredado (DV, No2). 
El Papa insiste que la religión católica es para la humanidad y es precisamente en virtud de su ciencia de Dios que puede conocer al hombre, al hombre verdadero, al hombre integral. Insiste que para conocer al hombre es necesario conocer a Dios (Pablo VI, 1965, No7). La Educación religiosa, tienen un profundo significado religioso, "no siendo otra cosa que una potente y amistosa invitación a la humanidad de hoy a encontrar de nuevo la vía del amor fraterno, a aquel Dios de quien alejarse es caer, a quien dirigirse es levantarse, en quien permanecer es estar firme, a quien volver es renacer, en quien habitar es vivir" (Pablo VI, 1965, No8).

\section{Conclusión}

¿Cómo aprender a vivir juntos? Esta pregunta representa un desafío en un contexto de sociedad fragmentada. Ella, más que pluralista, se ha constituido en una realidad pluralista, atomizada, no dialogante. Ante muchos hechos y debates sobre el sentido de nuestra convivencia, pareciera que estamos ante una relación social donde el núcleo de la identidad se ha desconfigurado y no se aceptan las distintas identidades en el libre juego de la razón pública. La constatación es que aún no hemos encontrado respuesta a esta pregunta; más bien, los distintos sectores, entre los cuales a veces los católicos nos encontramos, queremos imponer nuestras visiones sobre el hombre y el mundo. Esta pregunta se hace desde la convicción antropológica de ser seres relacionales que nos hacemos en y para otros. La comunidad es nuestro lugar de realización como personas, para lo cual es necesario reconocernos como iguales y valorar la riqueza de nuestras diferencias. 
Alfonso Valenzuela Aguirre | Aprendiendo a vivir juntos en una sociedad plural: aporte de la Educación Religiosa Escolar Católica (EREC)

\section{REFERENCIAS BIBLIOGRÁFICAS}

Campos, H. R. (2008). Incertidumbre y Complejidad: Reflexiones acerca de los retos y dilemas de la pedagogía contemporánea. Recuperado de: www.redalyc.org/pdf/447/44780102.pdf

Conferencia Episcopal de Chile (2005). Programa de Religión Católica: Sector de aprendizaje Religión. Santiago, Chile: SM Ediciones.

Congregación para la Educación Católica. (2014). Educar para el diálogo intercultural en la escuela católica: Vivir juntos para una civilización del amor. Ciudad del Vaticano, El Vaticano: Librería Editrice Vaticana.

Cox, C. (s.f.). Oportunidades de aprendizaje escolar de la ciudadanía en América Latina: Currículos comparados. Recuperado de: https://www.researchgate.net/.../228803072_Oportunidades_ de_aprendizaje_escolar_de...

Durkheim, É. (2007). Las formas elementales de la vida religiosa. Madrid, España: Akal.

Estrada, J. A. (2001). Razones y sin razones de la creencia religiosa. Madrid, España: Trotta.

Juan Pablo II (1988). Christifideles Laici, Exhortación Apostólica sobre el papel del Laico. Santiago, Chile: Paulinas.

Kung, H. (1987). Teología para la postmodernidad. Madrid, España: Alianza Editorial.

Latinobarómetro. (2017). Informe 2017. Recuperado de: www latinobarometro.org/LATDocs/F00006433InfLatino barometro2017.pdf

Luckmann, T. (2008). Conocimiento y sociedad. Ensayos sobre la acción, religión y comunicación. Madrid, España: Trotta. 
Pablo VI (1965). Clausura de la cuarta etapa conciliar. Recuperado de: https://www.inmaculadamg.org.ar/images/stories/formacion/ pablo_vi/Clausura_Cuarta_Etapa_Conciliar.html

Peña, W. (2007). El pensamiento complejo y los desafíos de la educación del siglo XXI. Recuperado de: https://dialnet.unirioja.es/servlet/ articulo?codigo $=4038508$

Pérez Gómez, Á. (1998). La cultura escolar en la sociedad neoliberal. Madrid, España: Mirata.

PNUD\&UNICEF. (2014). El papel de la educación en la formación del bienestar subjetivo para el desarrollo humano. Santiago, Chile: PNUD\&UNICEF.

Montes, C. (2018). Chile es el país de América Latina que peor evalúa al Papa. Pressreader. Recuperado de: https://www.pressreader.com/ chile/la-tercera/20180113/281612420804087

Congregación para la Educación Católica. (2014). Educar para el diálogo Intercultural en la escuela católica: Vivir juntos para una civilización del amor. Ciudad del Vaticano, El Vaticano: Librería Editrice Vaticana.

Touraine, A. (1997). ¿Podremos vivir juntos? México D.F., Mexico: Fondo de Cultura Económica.

Von Balthasar, H. (1979). La verdad es sinfónica. Madrid, España: Encuentro.

Yaksic, M. (2011). Politica y religión. Santiago, Chile: Ediciones Universidad Alberto Hurtado.

Fecha de recepción: 8 de julio de 2018

Fecha de aceptación: 20 de julio de 2018 